\title{
ALFACE E JATEIKAÁ EM CULTIVO SOLTEIRO E CONSORCIADO: PRODUÇÃO E ATIVIDADE ANTIOXIDANTE
}

\author{
Lettuce and jateikaá in single culture and intercropped: production and antioxidant activity
}

\author{
José Hortêncio Mota ${ }^{1}$, Maria do Carmo Vieira², Cláudia Andréa Lima Cardoso ${ }^{3}$
}

\begin{abstract}
RESUMO
Conduziu-se este estudo, com o objetivo de avaliar o crescimento e a produção de alface (Lactuca sativa L.) e jateikaá (Achyrocline alata (Kunth) DC.) em cultivo solteiro e em consórcio. Os tratamentos em estudo foram três e quatro fileiras de alface por canteiro, duas fileiras de jateikaá espaçadas de $35 \mathrm{~cm}$ e $50 \mathrm{~cm}$, quatro fileiras de alface alternadas com duas fileiras de jateikaá $\left(A_{25} J_{50}\right)$ e três fileiras de alface alternadas com duas fileiras de jateikaá $\left(A_{35} J_{35}\right)$. Foi utilizado o delineamento blocos casualizados, com quatro repetições. Foram avaliadas as massas frescas e secas, diâmetro e altura das cabeças de alface, massas frescas e secas das inflorescências e das partes aéreas sem inflorescências de jateikaá. Realizou-se o teste antioxidante para amostras de inflorescências de jateikaá nos tratamentos estudados. O tipo de cultivo e os espaçamentos entre fileiras não influenciaram significativamente as características avaliadas para alface e para o jateikaá, com exceção das massas fresca e seca de inflorescências, cuja produção foi superior no espaçamento de $50 \mathrm{~cm}$. A altura média obtida para as plantas de jateikaá foi de 1,12 m. A razão de área equivalente para o consórcio $A_{25} J_{50}$ foi de 1,87 e para o $A_{35} J_{35}$ foi de 2,10 . No caso de recomendação agronômica, optar-se-ía pelo consórcio $A_{35} \mathrm{~J}_{35}$. Observou-se atividade antioxidante em todas as amostras analisadas, sendo que o padrão de inibição apresentou semelhança tanto para cultivo solteiro quanto para o consorciado, demonstrando que os constituintes químicos do jateikaá apresentaram um alto potencial antioxidante.
\end{abstract}

Termos para indexação: Lactuca sativa, alface, Achyrocline alata, jateikaá, rendimento, sistemas de cultivo.

\begin{abstract}
This study aimed to evaluate the production of lettuce (Lactuca sativa L.) e jateikaá (Achyrocline alata (Kunth) DC.) as a single culture and intercropped. The treatments in study were three and four rows of lettuce and two rows of jateikaá spaced $35 \mathrm{~cm}$ or $50 \mathrm{~cm}$, four rows of lettuce alternated with two rows of jateikaá $\left(A_{25} J_{50}\right)$ and three alternated rows of lettuce with two rows of jateikaá $\left(\mathrm{A}_{35} \mathrm{~J}_{35}\right)$. The experiment design was randomized blocks, with four replications. Fresh and dry masses, diameter and height of the lettuce heads and height, fresh and dry masses of inflorescence and aerial parts without inflorescence of jateikaá were evaluated. The antioxidant activity of jateikaá's inflorescence was studied. The culture type and spacing between rows did not influence the characteristics evaluated for lettuce and for jateikaá, with exception of the fresh and dry masses of inflorescences, with production was superior in the $50 \mathrm{~cm}$ spacing of plants with height average of $1.12 \mathrm{~m}$ for the jateikaá plants. The land equivalent ratio, for intercropping $A_{25} J_{50}$ was 1.88 and for the $A_{35} J_{35}$ was 2.05. Intercropping $A_{35} J_{35}$ might be recommended. Antioxidant activity was observed in all samples. The inhibition standard was similar for both single culture and intercropping, demonstrating that the chemical constituent of jateikaá had presented a high antioxidant potential.
\end{abstract}

Index terms: Lactuca sativa, lettuce, Achyrocline alata, jateikaá, yield, cultivation systems.

(Recebido em 28 de agosto de 2008 e aprovado em 23 de outubro de 2009)

\section{INTRODUÇÃO}

A associação ou consórcio de culturas tem sido uma das formas de aumentar a produtividade e o lucro por unidade de área entre os pequenos agricultores (Caetano et al., 1999). Nessa prática, o objetivo tem sido o de maximizar a utilização de recursos ambientais e da área, melhorar o controle de pragas, doenças e plantas daninhas, diminuir o uso de insumos como fertilizantes e agrotóxicos e promover o equilíbrio ecológico. As vantagens dessa prática podem ser muito bem aproveitadas no cultivo de hortaliças, setor agrícola caracterizado por intenso manejo e exposição do solo, dificuldade no controle de plantas daninhas, uso intensivo de defensivos agrícolas, fertilizantes, irrigação, manejo da cultura que proporcionam consideráveis impactos ambientais, entre outras práticas culturais (Silva, 1983; Sullivan, 2003).

Contudo, existe uma lacuna no estudo da utilização de consórcios, decorrente da escassez de dados relacionados aos sistemas de consórcio entre espécies de plantas medicinais ou de plantas medicinais com hortaliças. Alguns casos de consórcio de plantas medicinais são

\footnotetext{
1Universidade Federal de Goiás/UFG - Campus Jataí/CAJ - Rodovia BR 364 - Km 192 - Cx. P. 03 - 75800-000 - Jataí, GO - hortenciomota@terra.com.br 2Universidade Federal da Grande Dourados/UFGD - Faculdade de Ciências Agrárias/FCA - Dourados, MS

3Universidade Estadual de Mato Grosso do Sul/UEMS - Departamento de Química - Dourados, MS
} 
usados por produtores em hortos caseiros, mas sem referência científica dos resultados. Assim, considerando a valorização do uso de plantas para fins medicinais e as crescentes procuras por essa matéria-prima, são necessários estudos que propiciem informações que permitam maximizar os processos de produção de biomassa vegetal, mantendo ou ampliando os teores de substâncias de interesse.

Entre as hortaliças para cultivo consorciado, podese citar a cultura da alface (Lactuca sativa L.) que se destaca como cultura de grande importância econômica e alimentar (Mota et al., 2003). Seu consumo está relacionado à facilidade de aquisição e baixo custo, além de ter propriedades calmantes, fácil digestão e, principalmente, baixa caloria, podendo ser utilizada em dieta para emagrecimento (Filgueira, 2000). Segundo Lorenzi \& Matos (2002), a literatura etnobotânica registra para esta planta atividade levemente laxante, diurética, antiácida e antirreumática destacando-se sua facilidade de cultivo.

Dentre as diversas plantas medicinais com potencial para utilização em consórcios no Estado do Mato Grosso do Sul, destacam-se a espécie Achyrocline alata (Kunth) DC. (jateikaá) (Sangalli et al., 2002), a qual é caracterizada pela rusticidade que favorece seu cultivo (Vieira et al., 2001; Silva et al., 2002) e pela potencialidade de utilização na indústria farmacêutica (Desmarchelier et al., 1998), ou medicinal. O jateikaá possui propriedades digestivas, colagoga, eupéptica, antiespamódica, carminativa, antiinflamatória e emenagoga, já cientificamente comprovadas (Simões et al., 1995) entre outras ainda a serem estudadas.

Face a importância de se avaliar o desempenho dos cultivos consorciados regionalmente, neste estudo, objetivou-se avaliar a produtividade de alface e jateikaá em cultivo solteiro e consociado, bem como avaliar a atividade antioxidante das inflorescências de jateikaá, nas condições ambientais de Dourados-MS.

\section{MATERIAL E MÉTODOS}

O experimento foi conduzido, no período de agosto de 2006 a julho de 2007, no Horto de Plantas Medicinais (HPM) da Universidade Federal da Grande Dourados (UFGD), em Dourados-MS (latitude 22 $2^{\circ} 11^{\prime} 43^{\prime \prime S}$, longitude 54 $56^{\circ} 08^{\prime}$ 'W e altitude de $458 \mathrm{~m}$ ). O clima da região, segundo a classificação de Köppen, é Mesotérmico Úmido; do tipo Cwa, com precipitação média anual de $1500 \mathrm{~mm}$ e temperatura média anual de $22^{\circ} \mathrm{C}$.

O solo da área experimental é um latossolo roxo distrófico, textura argilosa, originalmente sob vegetação de cerrado. A análise química das amostras retiradas da área experimental na camada de 0 a $20 \mathrm{~cm}$ de profundidade. A análise da amostra revelou os seguintes valores: $\mathrm{pH}\left(\mathrm{H}_{2} \mathrm{O}\right)=5,7 ; \mathrm{P}=128 \mathrm{mg} \mathrm{dm}^{-3} ; \mathrm{K}^{+}=5,1 \mathrm{cmolc} \mathrm{dm}^{-3}$; $\mathrm{Ca}^{++}=67,6 \mathrm{cmolc} \mathrm{dm}^{-3} ; \mathrm{Mg}^{++}=22,6 \mathrm{cmolc} \mathrm{dm}^{-3} ; \mathrm{V}=71 \% \mathrm{e}$ M.O. $=30,9 \mathrm{~g} \mathrm{dm}^{-3}$.

Foram constituídos seis tratamentos, da seguinte forma: três fileiras de alface espaçadas de $0,35 \mathrm{~m}\left(\mathrm{~A}_{0,35}\right)$; quatro fileiras de alface espaçadas de $0,25 \mathrm{~m}\left(\mathrm{~A}_{0,25}\right)$; duas fileiras de jateikaá espaçadas de $0,50 \mathrm{~m}\left(\mathrm{~J}_{0,50}\right)$; duas fileiras de jateikaá espaçadas de $0,35 \mathrm{~m}\left(\mathrm{~J}_{0,35}\right)$; quatro fileiras de alface espaçadas de $0,25 \mathrm{~m}$ alternadas com duas fileiras de jateikaá espaçadas de $0,50 \mathrm{~m}\left(\mathrm{~A}_{0,25} \mathrm{~J}_{0,50}\right)$; três fileiras de alface espaçadas de $0,35 \mathrm{~m}$ alternadas com duas fileiras de jateikaá espaçadas de $0,35 \mathrm{~m}\left(\mathrm{~A}_{0,35} \mathrm{~J}_{0,35}\right)$. Os seis tratamentos foram arranjados no delineamento experimental blocos casualizados, com quatro repetições. Os espaçamentos entre plantas de jateikaá foram de $0,40 \mathrm{~m}$ e para a cultura da alface $0,20 \mathrm{~m}$. A área útil das parcelas foi de 2,4 $\mathrm{m}^{2}(1,0 \mathrm{~m}$ de largura x 2,4 m de comprimento).

Em razão do fato de suas sementes serem pequenas, o jateikaá foi semeado inicialmente em bandejas de plástico com substrato comercial Plantmax ${ }^{\circledR}$ e, posteriormente, transplantadas individualmente para bandejas de poliestireno de 128 células.

Para a cultura da alface, a semeadura foi realizada em bandejas de poliestireno com 128 células em substrato comercial para hortaliças. Ao atingirem $5 \mathrm{~cm}$ de altura ou 4 a 6 folhas definitivas, foram transplantadas para o campo. A cultivar de alface utilizada foi a Babá de Verão Manteiga do grupo Repolhuda Lisa.

O preparo do solo constou de aração e gradagem, com posterior levantamento de canteiros, com rotoencanteirador. A adubação de plantio foi realizada com cama-de-frango semidecomposta, na dose de $10 \mathrm{t} \mathrm{ha}^{-1}$. Durante o ciclo da cultura, foram realizadas capinas manuais para controle de plantas infestantes. As irrigações foram feitas por aspersão com o intuito de manter o solo sempre úmido, para o completo desenvolvimento das plantas. Não foram utilizados produtos químicos para controle de pragas ou doenças.

A alface foi colhida aos 42 dias após o transplantio, quando as cabeças apresentaram completo desenvolvimento, cortando-se as plantas rente ao solo. Na colheita, foram avaliadas as massas frescas e secas das partes aéreas, além do diâmetro e altura das plantas.

Durante o ciclo de cultivo do jateikaá foram, mensalmente, medidas com auxílio de uma trena, as alturas das plantas em cada parcela, a partir de 30 dias após o transplante (DAT) até a colheita. O jateikaá foi colhido aos 360 DAT, sendo colhidas duas plantas por parcela, sendo 
cortadas rente ao solo e avaliadas as massas frescas e secas das inflorescências e das partes aéreas sem inflorescências.

Para obtenção da massa seca, secou-se o material em estufa com circulação forçada de ar a $38 \pm 4^{\circ} \mathrm{C}$, até massa constante.

Às médias dos dados de altura de plantas de jateikaá foram ajustadas equações de regressão em função dos dias após transplante, para cada tratamento. Os demais dados foram submetidos à análise de variância e quando houve significância pelo teste $\mathrm{F}$, as médias foram testadas por Tukey até 5\% de probabilidade (Gomes, 2000).

O consórcio foi avaliado utilizando-se a expressão da Razão de Área Equivalente (RAE), proposta por Caetano et al.(1999):

$$
\mathrm{RAE}=\frac{\mathrm{Ac}}{\mathrm{As}}+\frac{\mathrm{Jc}}{\mathrm{Js}}
$$

em que:

Ac = produção de alface em consorciação;

$\mathrm{Jc}=$ produção de jateikaá em consorciação;

As = produção de alface em cultivo solteiro;

Js = produção de jateikaá em cultivo solteiro.

Para avaliar a atividade antioxidante, as inflorescências secas de jateikaá foram trituradas em moinho de facas e colocadas em embalagens de saco plástico.

Realizou-se o teste antioxidante com o radical livre DPPH (1,1 - difenil - 2 picril - hidrazila) com metanol empregando uma solução preparada de DPPH a 0,004\% em metanol. Das amostras foram retirados os volumes de 20, 200 e $1000 \mathrm{~mL}$. No caso dos volumes menores que 1000 $\mathrm{mL}$ estes foram avolumados para $1000 \mathrm{~mL}$ empregando como solvente o metanol. A cada $1 \mathrm{~mL}$ da solução preparada foram adicionados $2 \mathrm{~mL}$ da solução de DPPH. Por meio das absorbâncias resultantes, foi calculado a \% absorbância, onde foi plotado um gráfico de \% do percentual de inibição versus concentração (Mokbel \& Hashinaga, 2006).

A atividade antioxidante das amostras foram expressas como percentual de inibição da oxidação (\% $\mathrm{A})$ :

$$
\% \Delta \mathrm{o}=\frac{(\mathrm{Ao}-\mathrm{A})}{\mathrm{Ao}} \times 100
$$

em que:

Ao = absorbância do DPPH em metanol decorridos 30 minutos de reação,

$\mathrm{A}=$ à absorbância da amostra em DPPH decorridos 30 minutos de reação.
O padrão utilizado para a atividade antioxidante foi a quercetina sendo preparadas soluções em concentrações entre 20-320 $\mu \mathrm{g} \mathrm{mL}^{-1}$ e o comprimento de onda de leitura foi de $517 \mathrm{~nm}$.

Todas as amostras foram analisadas em triplicata e comprimento de onda de leitura de $517 \mathrm{~nm}$, sendo que as análises foram realizadas no Laboratório de Química da Universidade Estadual de Mato Grosso do Sul em Dourados-MS.

\section{RESULTADOS E DISCUSSÃO}

Para as características avaliadas de alface massa fresca e seca, diâmetro e altura, não houve diferença significativa entre arranjo de plantas e fileiras no canteiro (Tabela 1).

A produtividade de massa fresca e seca de alface não diferiu significativamente em função do consórcio e nem do número de fileiras no canteiro, bem como não houve interação entre os tratamentos, demonstrando que os cultivos mais adensados para essa cultura não causariam diminuição na produção.

Observa-se que não houve relação entre diâmetro e altura de plantas. No cultivo solteiro, observou-se tendência das plantas serem maiores, e mais prostadas, o que para o cultivo em consórcio houve relação inversa, provavelmente, em razão da concorrência por luz, entre outros fatores.

Resultados semelhantes foram obtidos por Munarim et al. (2005) que, estudando o consórcio de alface e jateikaá, verificaram que as produções de massa fresca comercializável das cabeças da alface não foram influenciadas significativamente pelo arranjo de plantas ou pelo de número de fileiras no canteiro.

Para as características avaliadas de jateikaá (Tabela 2), massas frescas e secas de plantas e altura de planta, não houve diferença significativa entre arranjo de plantas e espaçamentos entre fileiras, com exceção das massas fresca e seca de inflorescências, cuja produção foi superior no espaçamento de $50 \mathrm{~cm}$, provavelmente, seja em razão da menor competição por água, luz e nutrientes.

Apesar de não diferenciar-se significativamente, observou-se uma redução de $17,8 \%$ na produção do jateikaá solteiro em relação ao consorciado.

O jateikaá apresentou em todos os tratamentos resposta de crescimento quadrática (Figura 1), atingindo média de 1,12 $\mathrm{m}$ aos 360 dias. As alturas observadas foram semelhantes às obtidas por Paes et al. (2007), ao analisarem crescimento e produção de jateikaá em cultivo solteiro e consorciado com rabanete sob dois arranjos de plantas. 
Os resultados da RAE de 1,87 para o consórcio $\mathrm{A}_{25} \mathrm{~J}_{50}$ e 2,10 para o consórcio $\mathrm{A}_{35} \mathrm{~J}_{35}$, considerando massa seca de inflorescências de jateikaá e massa fresca de folhas de alface, indicam que os consórcios foram efetivos. Deduzse que, no monocultivo, as espécies exigiriam $87 \%$ e $110 \%$ a mais de área que sob consórcio para produzir a mesma quantidade total obtida no consórcio.

Munarin et al. (2005) observaram RAE de 3,01 para o consórcio da jateikaá com alface, sob duas e três fileiras no canteiro, respectivamente, e RAE de 1,95, sob quatro fileiras de alface e duas de jateikaá. Provavelmente, a diferença entre resultados seja decorrente da adaptação das plantas de jateikaá (população) associada aos fatores água, luz e nutrientes. Ajalla et al. (2009), avaliando o crescimento e a produção de biomassa de marcela em cultivo solteiro e consorciado com tansagem (Plantago major L.), também obtiveram valores de IEA superiores a 1 , demonstrando eficiência do consórcio utilizando a espécie.
Os valores obtidos para a RAE mostram-se coerentes com as citações de Sullivan (2003), Heredia Zárate et al. (2003), Salvador et al. (2004), Harder et al. (2005), Nascimento et al. (2007) e Moraes et al. (2008), de que o aumento da produtividade por unidade de área é uma das razões mais importantes para se cultivar duas ou mais culturas no sistema de consorciação, porque permite melhor aproveitamento da terra e de outros recursos disponíveis.

Observou-se atividade antioxidante em todas as amostras analisadas (Figura 2), sendo que o percentual de inibição foi crescente à medida que foi maior a concentração do antioxidante.

Os resultados obtidos demonstram tanto o cultivo solteiro quanto o cultivo consorciado apresentaram atividade antioxidante. $\mathrm{O}$ padrão de inibição apresentou padrão semelhante tanto para cultivo solteiro quanto consorciado de jateikaá, demonstrando que os constituintes químicos do jateikaá apresentaram um alto potencial

Tabela 1 - Produções de massas frescas e secas, diâmetro e altura de alface nos sistemas de cultivo solteiro e consorciado com jateikaá, sob três e quatro fileiras no canteiro.

\begin{tabular}{lcccc}
\hline \multicolumn{1}{c}{ Fator } & $\begin{array}{c}\text { Massa fresca } \\
\left(\mathrm{kg} \mathrm{ha}^{-1}\right)\end{array}$ & $\begin{array}{c}\text { Massa seca } \\
\left(\mathrm{kg} \mathrm{ha}^{-1}\right)\end{array}$ & $\begin{array}{c}\text { Diâmetro } \\
(\mathrm{cm})\end{array}$ & $\begin{array}{c}\text { Altura } \\
(\mathrm{cm})\end{array}$ \\
\hline Sistema de cultivo & & & & \\
\hline Solteiro & $2906,13 \mathrm{a}$ & $204,98 \mathrm{a}$ & $27,92 \mathrm{a}$ & $18,48 \mathrm{a}$ \\
Consórcio & $2891,44 \mathrm{a}$ & $223,41 \mathrm{a}$ & $26,05 \mathrm{a}$ & $19,10 \mathrm{a}$ \\
\hline Fileiras no canteiro & & & & \\
\hline Três & $2553,53 \mathrm{a}$ & $223,68 \mathrm{a}$ & $27,10 \mathrm{a}$ & $17,88 \mathrm{a}$ \\
Quatro & $3244,04 \mathrm{a}$ & $204,71 \mathrm{a}$ & $26,87 \mathrm{a}$ & $19,70 \mathrm{a}$ \\
\hline C.V. $(\%)$ & 27,80 & 30,57 & 9,98 & 9,87 \\
\hline
\end{tabular}

Médias seguidas pelas mesmas letras, nas colunas, não diferem ( $p<0,05)$.

Tabela 2 - Produções de massas frescas e secas de plantas e inflorescência e altura de jateikaá nos sistemas de cultivo solteiro e consorciado com alface, nos espaçamentos de 35 e $50 \mathrm{~cm}$ entre fileiras.

\begin{tabular}{lccccc}
\hline \multicolumn{1}{c}{ Fator } & $\begin{array}{c}\text { Massa fresca } \\
\left(\mathrm{t} \mathrm{ha}^{-1}\right)\end{array}$ & $\begin{array}{c}\text { Massa seca } \\
\left(\mathrm{t} \mathrm{ha}^{-1}\right)\end{array}$ & $\begin{array}{c}\text { Massa fresca } \\
\left(\mathrm{t} \mathrm{ha}^{-1}\right)\end{array}$ & $\begin{array}{c}\text { Massa seca } \\
\left(\mathrm{t} \mathrm{ha}^{-1}\right)\end{array}$ & $\begin{array}{c}\text { Altura } \\
(\mathrm{cm})\end{array}$ \\
\hline Sistema de cultivo & & & & & \\
\hline Solteiro & $28,65 \mathrm{a}$ & $13,17 \mathrm{a}$ & $0,21 \mathrm{a}$ & $0,09 \mathrm{a}$ & $113,14 \mathrm{a}$ \\
Consórcio & $27,48 \mathrm{a}$ & $14,32 \mathrm{a}$ & $0,20 \mathrm{a}$ & $0,08 \mathrm{a}$ & $103,17 \mathrm{a}$ \\
\hline Espaçamento entre fileiras & & & & \\
\hline $35 \mathrm{~cm}$ & $28,46 \mathrm{a}$ & $13,57 \mathrm{a}$ & $0,17 \mathrm{~b}$ & $0,07 \mathrm{~b}$ & $112,17 \mathrm{a}$ \\
$50 \mathrm{~cm}$ & $27,66 \mathrm{a}$ & $13,93 \mathrm{a}$ & $0,23 \mathrm{a}$ & $0,10 \mathrm{a}$ & $104,14 \mathrm{a}$ \\
\hline C.V. $(\%)$ & 24,11 & 21,34 & 19,67 & 17,82 & 12,01 \\
\hline
\end{tabular}

Médias seguidas pelas mesmas letras, nas colunas, não diferem $(\mathrm{p}<0,05)$. 


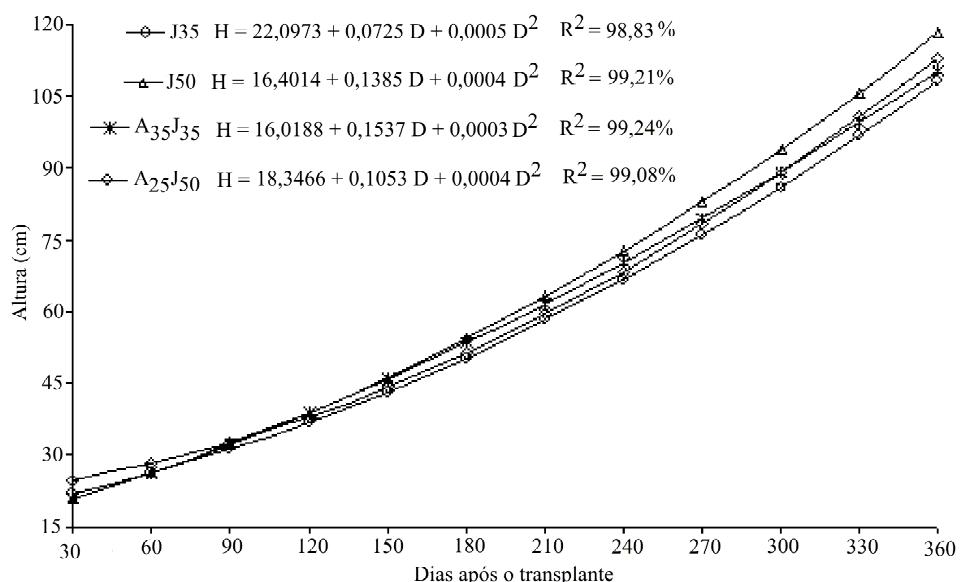

Figura 1 - Altura de plantas de jateikaá com diferentes arranjos de plantas e espaçamentos, em função de dias após o transplante.

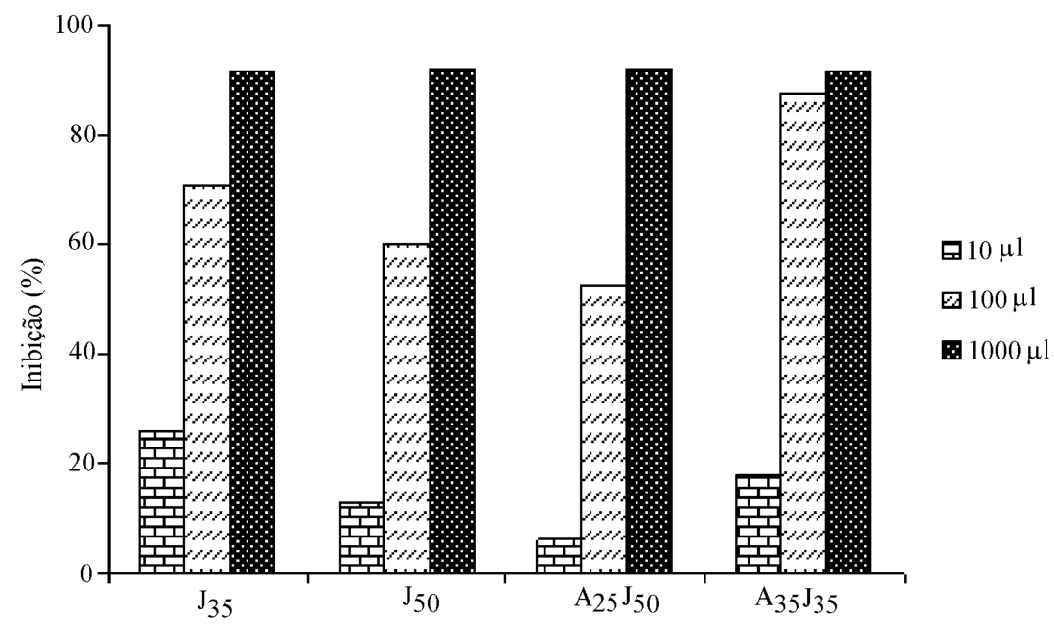

Figura 2 - Percentual de inibição de amostras de inflorescências de jateikaá. Em que: $\mathbf{J}_{50}=$ cultivo solteiro de jateikaá com espaçamento de $0,50 \mathrm{~m}$ entre plantas; $\mathrm{J}_{35}=$ cultivo solteiro de jateikaá com espaçamento de $0,35 \mathrm{~m}$ entre plantas; $\mathrm{A}_{35} \mathrm{~J}_{35}=$ cultivo consorciado sendo três fileiras de alface espaçadas de $0,35 \mathrm{~m}$ e duas fileiras de jateikaá espaçadas de $0,35 \mathrm{~m} ; \mathrm{A}_{25} \mathrm{~J}_{50}=$ cultivo consorciado sendo quatro fileiras de alface espaçadas de $0,25 \mathrm{~m}$ alternadas com duas fileiras de jateikaá espaçadas de $0,50 \mathrm{~m}$.

antioxidante; provavelmente em razão da presença de compostos fenólicos (Broussalis et al., 1988).

Pelloso (2007), estudando a atividade antioxidante em amostras (folha, caule e raiz) de fáfia (Pfaffia glomerata (Spreng.) Pedersen) observou que todas as amostras apresentaram propriedade antioxidante, entretanto, a intensidade dessa ação foi diferenciada entre elas.

\section{CONCLUSÕES}

Os sistemas de cultivo e os espaçamentos entre fileiras não influenciaram as características avaliadas para alface e jateikaá.
No caso de recomendação agronômica, optar-se-ía pelo consórcio três fileiras de alface (espaçadas de $35 \mathrm{~cm}$ ) alternadas com duas fileiras de jateikaá, com espaçamento de $50 \mathrm{~cm}$.

As inflorescências de jateikaá apresentaram atividade antioxidante, tanto em cultivo solteiro quanto consorciado.

\section{AGRADECIMENTOS}

Ao CNPq, pela bolsa concedida e à FUNDECT-MS, pelo apoio financeiro. 


\section{REFERÊNCIAS BIBLIOGRÁFICAS}

AJALLA, A.C. A.; VIEIRA, M. do C.; ZARATE, N. A. H.; MOTA, J. H.; SOUZA, T. M. de. Produtividade da marcela [Achyrocline satureioides (Lam.) DC.] em cultivo solteiro e consorciado com tansagem (Plantago major L. ). Ciência e Agrotecnologia, Lavras, v. 33, n. 2, p. 488-495, mar./abr., 2009.

BROUSSALIS, A.M.; FERRARO, G.E.; GURNI, A.; COUSSIO, J.D. Phenolic constituents of four Achyrocline species. Biochemical Systematics and Ecology, Oxford, v.16, p.401-402, 1988.

CAETANO, L.C.S.; FERREIRA, J.M.; ARAÚJO, M. de. Produtividade da alface e cenoura em sistema de consorciação. Horticultura Brasileira, Brasília, v.17, n.2, p.143-146, 1999.

DESMARCHELIER, C.; COUSSIO, J.; CICCIA, G. Antioxidant and free radical scavengingeffects in extracts of the medicinal herb Achyrocline satureioides (Lam.) DC. ("marcela"). Brazilian Journal of Medical and Biological Research, Ribeirão Preto, v.31, n.9, p.1163-1170, 1998.

FILGUEIRA, F.A.R. Novo manual de olericultura: agrotecnologia moderna na produção e comercialização de hortaliças. Viçosa, MG: UFV, 2000. 402p.

GOMES, F.P. Curso de estatística experimental. 14.ed. Piracicaba: [s.n.], 2000. 468p.

HARDER, W.C.; ZARATE, N.A.H.; VIEIRA, M.C. Produção e renda bruta de rúcula (Eruca sativa Mill.) cultivada e de almeirão (Cichorium intybus L.) amarelo em cultivo solteiro e consorciado. Ciência e Agrotecnologia, Lavras, v.29, n.4, p.775-785, 2005.

HEREDIA ZÁRATE, N.A.; VIEIRA, M.C.; WEISMANN, M.; LOURENÇÃO, A.L.F. Produção e renda bruta de cebolinha e salsa em cultivo solteiro e consorciado Horticultura Brasileira, Brasília, v.21, n.3, p.574-577, 2003.

LORENZI, H.; MATOS, F.J.A. Plantas medicinais no Brasil: nativas e exóticas cultivadas. Nova Odessa: Instituto Plantarum, 2002. 544p.

MOKBEL, M.S.; HASHINAGA, F. Evaluation of the antioxidant activity of extracts from buntan (Citrus grandis Osbeck) fruit tissues. Food Chemistry, London, v.94, p.529-534, 2006.
MORAES, A. A.; VIEIRA, M. do C.; ZARATE, N. A. H.; TEIXEIRA, I. R.; RODRIGUES, E. T. Produção da capuchinha em cultivo solteiro e consorciado com os repolhos verde e roxo sob dois arranjos de plantas. Ciência e Agrotecnologia, Lavras, v. 32, n. 4, p. 11951202, jul./ago., 2008.

MOTA, J.H.; YURI, J.E.; FREITAS, S.A.C.; RODRIGUES JÚNIOR, J.C.; RESENDE, G.M.; SOUZA, R.J. Avaliação de cultivares de alface americana durante o verão em Santana da Vargem, MG. Horticultura Brasileira, Brasília, v.21, n.2, p.234-237, 2003.

MUNARIN, E.E.O.; VIEIRA, M.C.; HEREDIA ZÁRATE, N.A.; MOTA, J.H. Produção de Achyrocline alata em cultivo solteiro e consorciado com alface cultivada com três ou quatro fileiras no canteiro. In: CONGRESSO BRASILEIRO DE OLERICULTURA, 45., 2005, Fortaleza. Resumos... Fortaleza: SOB, 2005.

NASCIMENTO, E. X. do; MOTA, J. H.; VIEIRA, M. do C.; ZARATE, N. A. H. Produção de biomassa de Pfaffia glomerata (Spreng.) Pedersen e Plantago major L. em cultivo solteiro e consorciado. Ciência e Agrotecnologia, Lavras, v. 31, n. 3, p. 724-730, maio/jun., 2007.

PAES, C.L.; VIEIRA, M.C.; BOTTEGA, S.P.; PADILHA, N.S.; ZÁRATE, N.A.H.; MOTA, J.H. Produção do jateikaá (Achyrocline alata L.) em cultivo solteiro e consorciado com rabanete (Raphanus sativus L.), sob dois arranjos de plantas. In: ENCONTRO DE INICIAÇÃO CIENTÍFICA UFGD/UEMS, 1., 2007, Dourados. Resumos expandidos e trabalhos completos... Dourados: UFGD/UEMS, 2007. CD-ROM.

PELLOSO, I.A.O. Produção e atividade antioxidante de Pfafffia glomerata em função de espaçamentos e arranjo de plantas em duas épocas de colheita. 2006. 37f.

Dissertação (Mestrado em Produção Vegetal)-Universidade Federal da Grande Dourados, Dourados, 2006.

SALVADOR, D.J.; HEREDIA ZÁRATE, N.; VIEIRA, M.C. Produção e renda bruta de cebolinha e de almeirão, em cultivo solteiro e consorciado. Acta Scientiarum, Maringá, v.26, n.4, p.491-496, 2004.

SANGALLI, A.; VIEIRA, M.C.; ZARATE, N.A.H. Levantamento e caracterização de plantas nativas com propriedades medicinais em fragmentos florestais e de cerrado de Dourados-MS, numa visão etnobotânica. Acta Horticulturae, Leuven, n.569, p.173-184, 2002. 
SILVA, C.B.; VIEIRA, M.C.; ZARATE, N.A.H.; RAMOS, M.B.M. Produção de Achyrocline satureioides em função de populações de plantas e do uso de cama-deaviário In: SIMPÓSIO DE PLANTAS MEDICINAIS DO BRASIL, 17., 2002, Cuiabá. Anais... Cuiabá: SPMB, 2002.

SILVA, N.F. Consórcio de hortaliças. In: HEREDIA, M.C.V.; BURBA, J.L.; CASALI, V.W.D. (Coords.).

Seminários de olericultura. Viçosa, MG: UFV, 1983. p.119.

SIMÕES, C.M.O.; MENTZ, L.A.; IRGANO, B.E.;

STEHMANN, J.R. Plantas da medicina popular no Rio
Grande do Sul. 4.ed. Porto Alegre: UFRGS, 1995. 173p.

SULLIVAN, P. Intercropping principles and production practices. Fayetteville: ATTRA, 2003. 12p. Disponível em: 〈http://www.attra.org/attra-pub/PDF/intercrop.pdfy. Acesso em: 1 nov. 2004.

VIEIRA, M.C.; CASTEL, D.D.; ZARATE, N.A.H.; CAPUANO JÚNIOR, J.C.; MORAES, T.C. Crescimento e produção de Achyrocline satureioides em função de espaçamentos e arranjos de plantas. In: JORNADA PAULISTA DE PLANTAS MEDICINAIS, 5., 2001, Botucatu. Resumos... Botucatu: Unesp, 2001. p.73. 